\title{
"Rindo até da própria desgraça": o riso como avaliação encaixada em narrativas orais
}

\author{
Laughing even at your own misfortune: laugh as an embedded evaluation in oral
} narratives

\author{
Nair Daiane de Souza Sauaia VANSILER* \\ Universidade Federal do Pará (UFPA) \\ Juliana de Amorim MARQUES ${ }^{* *}$ \\ Universidade Federal do Pará (UFPA) \\ Regina Célia Fernandes CRUZ ${ }^{* * *}$ \\ Universidade Federal do Pará (UFPA)
}

\begin{abstract}
RESUMO: O modelo de narrativa oral proposto por Labov e Waletzky (1967) é o mais aplicado quando se analisa narrativas de experiência pessoal. Dentre as seis partes - Resumo, Orientação, Avaliação, Complicação, Resolução e Coda - que compõem a estrutura de uma narrativa de experiência pessoal, a Avaliação é considerada a de maior traço funcional, pois veicula toda o envolvimento emocional do narrador com o evento narrado. Análises formais da estrutura de narrativas orais de experiência pessoal nos moldes labovianos (LABOV; WALETZKY, 1967; LABOV, 1972) têm dado prioridade para evidenciar o papel dos elementos linguísticos na caracterização de suas seis partes (OLIVEIRA JR., 2000). O presente estudo, destoando dessa tendência, tem como objetivo demonstrar em que medida eventos avaliativos (LABOV, 1972; MELO, 2003) são codificados por elementos paralinguísticos e multimodais. Mais especificamente, analisamos, aqui, eventos avaliativos construídos por riso que garantem uma performance particular ao ato de narrar. Em um corpus de 12 narrativas orais de experiência pessoal foram identificados 133 eventos avaliativos, sendo 99 do tipo encaixado e 34 do tipo externo. Os resultados da análise quantitativa apontaram que 8 ocorrências de risos identificadas nesse corpus têm como preferência as avaliações do tipo encaixadas. Os dados também foram submetidos a um protocolo experimental para descrevê-los gestualmente, o GAT (SELTING et al., 2011). Constatamos que, como já apontado por Britton e Kerbrat-Orecchioni (1996), os aspectos paraverbais ou não verbais desempenham um papel importante nas interações verbais.
\end{abstract}

PALAVRAS-CHAVE: Narrativas. Avaliação. Risos.

ABSTRACT: The oral narrative model proposed by Labov and Waletzky (1967) is the most applied for analyzing personal experience narratives. Among the six parts - Summary, Orientation, Evaluation, Complication, Resolution and Coda - that make up the structure of a personal experience narrative, the Evaluation is considered the one with the greatest functional feature, since it conveys the narrator's emotional involvement with the narrated event. Formal analyzes from the structure of personal experience oral narratives in the Labovian pattern (LABOV; WALETZKY, 1967; LABOV, 1972) have given priority to highlight the role of linguistic elements in the characterization of its six parts (OLIVEIRA JR., 2000). This study, contrary to this trend, aims to demonstrate to what extent evaluative events (LABOV, 1972;

\footnotetext{
* Mestre em Estudos Linguísticos. Doutoranda em estudos Linguísticos no PPGL/UFPA. Bolsista CNPq. Belém/Pará. E-mail: nairsauaia@gmail.com

** Mestre em Estudos Linguísticos pela UFPA/PPGL. Belém/Pará. E-mail: juliana-2904@ hotmail.com

**** Doutora em Ciências Humanas pela Université de Provence. Belém/Pará. Pesquisadora do CNPq. Email: regina@ufpa.br
}

Revista Moara, n. 54, ago-dez 2019 ISSN: 0104-0944

Recebido em 31/08/2019

Avaliado em 24/11/2019 
MELO, 2003) are codified by paralinguistic and multimodal elements. More specifically, we analyzed evaluative events built by laugh that guarantee a particular performance to the act of narrating. In a corpus of 12 oral narratives of personal experience, 133 evaluative events were identified: 99 embedded and 34 external. The results of the quantitative analysis pointed out that eight occurrences of laugh identified in this corpus have the preference of embedded evaluations. The data were also submitted to an experimental protocol to describe them gesturally - GAT - (SELTING et al., 2011). As pointed out by Britton and Kerbrat-Orecchioni (1996), paraverbal or nonverbal aspects make an important role in verbal interactions.

KEYWORDS: Narratives. Evaluation. Laughs.

\section{Introdução}

O modelo proposto por Labov e Waletzky (1967) para descrever a estrutura formal da narrativa de experiência pessoal tem sido amplamente tomado como referência desde sua publicação. Segundo os autores, uma narrativa pode ser definida como sendo "um método de capitular experiências passadas, combinando uma sequência verbal de orações com uma sequência de eventos que (infere-se) ocorreram de fato" (LABOV, 1972, p. 359), além disso, o fato da narrativa remeter a um acontecimento em uma sequência temporal, com pelo menos duas orações, ter um evento e ser contável, caracteriza a recapitulação de experiências (LABOV; WALETZKY, 1967 e LABOV, 1972).

Dentre as seis partes - Resumo, Orientação, Avaliação, Complicação, Resolução e Coda - que compõem a estrutura de uma narrativa de experiência pessoal (LABOV; WALETZKY, 1967), a Avaliação é considerada a de maior traço funcional, pois veicula todo o envolvimento emocional do narrador com o evento narrado.

Estudos têm demonstrado que, no ato de narrar, para que se reproduzam, ou mesmo, percebam-se as partes integrantes das seções em uma narrativa oral são incorporados pelos narradores ao evento narrativo aspectos que garantem sua performance particular (OLIVEIRA JR., 2000), em especial, os elementos paraverbais ou não verbais.

Elegeu-se como contexto de observação neste artigo uma das partes da narrativa de experiência pessoal de maior poder funcional, a Avaliação, e mais precisamente dois de seus tipos de manifestação (LABOV; WALETZKY, 1967; LABOV, 1972): as do tipo Externa, caracterizadas pela interrupção da narrativa pelo 
narrador para comunicar seu ponto de vista sobre o fato narrado; e as do tipo Encaixada, que permitem ao narrador tecer uma avaliação sem interromper o fluxo narrativo.

Segundo Britton e Kerbrat-Orecchioni (1996), elementos avaliativos muito produtivos são os do tipo intensificadores, seja os linguísticos, como os intensificadores lexicais (advérbios ou adjetivos), seja os paralinguísticos ou gestuais, dentre os quais destacam-se o riso, objeto de estudo do presente artigo.

Objetivando descrever os recursos paraverbais e não verbais das avaliações nas narrativas de experiência pessoal (LABOV; WALETZKY, 1967; LABOV, 1972), em especial, o riso, primeiramente analisamos quantitativamente os trechos com eventos avaliativos do corpus selecionado, o qual inicialmente era composto por 12 narrativas. Um refinamento das análises foi realizado com o auxílio do software GAT (SELTING et al., 2011). Nesta última etapa, apenas foram analisados os trechos avaliativos contendo gestos ou elementos paralinguísticos, principalmente risos.

Para uma compreensão melhor do estudo aqui descrito, este artigo encontra-se assim estruturado: a seção 1 - apresentação do objeto - é destinada aos estudos sobre narrativas pessoais, em especial sobre Avaliação; a seção 2 - Métodos - apresenta a metodologia pela qual o corpus aqui foi analisado, mais especificamente o tratamento dos elementos prosódicos e gestuais; a seção 3 - Resultados - apresenta os resultados quantitativos e qualitativos das análises empreendidas. As duas últimas seções compreendem a conclusão e as referências.

\section{Apresentando o objeto}

Para Labov e Waletzky (1967) e Labov (1972), as narrativas de experiência pessoal estão descritas estruturalmente pelas seguintes seções: Resumo, Orientação, Complicação, Avaliação, Resolução e Coda.

Já a Orientação, conforme Labov e Waletzky (1967), situa-se normalmente no início da narrativa, ela é reconhecida por causa das informações e descrições sobre a(s) personagem(ns) e a localização espacial e temporal dos eventos a serem narrados; a Complicação, segundo os autores, é a parte fundamental na narrativa, pois constitui-se da sequência dos eventos narrados; já a Avaliação é típica das narrativas de experiência 
pessoal, já que expressa o sentido da validade da experiência do narrador para com o ouvinte.

Ainda segundo a descrição dos autores, a Resolução é o evento que encerra a Complicação, "sendo a parte da sequência narrativa que segue a Avaliação" (LABOV; WALETZKY, 1967, p. 9). Para eles, Avaliação e Resolução estão imbricadas na sequência dos eventos da narrativa, uma vez que a Avaliação não tem uma localização fixa na narrativa, assim, a delimitação da Resolução passa a ser feita em bases semânticas dos enunciados, ou seja, a parte narrada ou uma sequência de frases que soluciona o evento apresentado na Complicação narrada.

A Coda, para Labov e Waletzky (1967), é um elemento não essencial, pois constitui-se num mecanismo funcional, que faz com que a perspectiva verbal volte ao tempo presente, isto é, ao momento da enunciação, logo, não fazendo parte do encadeamento de eventos que a narrativa consequentemente apresenta (MACHADO, 1980). Para o autor, o Resumo é o elemento da narrativa que tem por finalidade preparar e reforçar o papel de Avaliação, é representada por uma ou duas cláusulas que sintetizam toda a história.

Quanto à Avaliação, que é objeto deste artigo, existem quatro tipos: Avaliação Externa, Avaliação Encaixada, Avaliação pelo fato e Avaliação por suspensão da ação (LABOV; WALETZKY, 1967; LABOV, 1972), levamos em conta neste artigo apenas os dois primeiros tipos.

A Avaliação Externa refere-se à interrupção, feita pelo narrador durante o relato, para comunicar diretamente qual o ponto de vista sobre o acontecimento narrado. A Avaliação Encaixada, por sua vez, refere-se à avaliação dada de forma indireta pelo narrador durante o relato, usando de carga dramática por meio de recursos linguísticos, sejam gramaticais, semânticos ou prosódicos.

Para exemplificar, apresentamos a transcrição do relato de NSF3NI05 ${ }^{1}$, participante de nosso corpus a partir da Análise da Conversação (MARCUSCHI, 1986):

\footnotetext{
${ }^{1}$ Está melhor descrito na subseção 2.2.

Revista Moara, n. 54, ago-dez 2019 ISSN: 0104-0944 
01 Meu namorado ia me/toda tarde ele ia em casa né? Aí ele viu que tava uma 02 arrumação que a gente ia: se mudar prum/pra fazenda no MURICITUBA. Aí ele 03 disse assim "não! Tu não vais! eu vou te roubar, eu venho cinco horas da tarde, 04 tu vai comigo?" eu digo "eu vou!" aí minha mãe arrumando a: mala, lou:ça um/ 05 aí tudo pra ir embora pra fazenda, né? Aí ele assobiou lá da casa do... da casa do 06 irmão dele que ficava na praça de São Sebastião. Aí fui ((bate com as duas mãos 07 indicando fuga)) eu corri e fui me embora, fui só com a roupa do corpo, né? Aí 08 ele foi pro cinema e eu fui pra casa dum amigo dele... um amigo meu, dele... e: aí 09 pronto! Ficaram desesperados em casa, o meu pai gritava "cadê Nair? Cadê a 10 minha filha? Eu quero a minha filha!" e a minha mãe dizia "Antoninho não grita! 11 Olha o público!" que ele disse "BANANA PRO PÚBLICO! BANANA PRO 12 PÚBLICO!" ele gritava banana ((risos)) e assim foi até que me encontraram, e 13 fizeram o casamento na ... pela manhã, sete horas da manhã na Igreja de Nossa Senhora da Conceição... em Viana no Maranhão ((sorri envergonhada e cobre a boca com a mão))

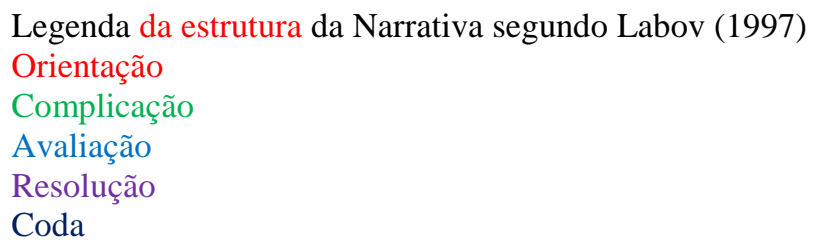

1a exemplifica uma Avaliação Externa. Neste caso, a narradora interrompe o relato sobre estar sendo roubada para casar, para fazer um comunicado extra de como ela estava nesta situação, a forma direta da avaliação que, neste caso, pode ser observada pelos verbos em $1^{\text {a }}$ pessoa e pela pergunta que finaliza a avaliação, que traz o entrevistador inclusive para a avaliação, de que realmente naquelas condições narradas, ela só podia estar apenas com a roupa do corpo, "né?!". Para o exemplo 1a usamos o seguinte trecho:

Exemplo 1a: "eu corri e fui me embora, fui só com a roupa do corpo, né?!"

O exemplo 1 b exemplifica uma Avaliação Encaixada. Neste caso, podemos observar a forma indireta na qual a narradora avalia: com o uso do riso envergonhado e cobrindo a boca com a mão, conjunto de informações que nos levam a crer, de forma indireta, que a narradora se sente envergonhada pelo conteúdo de seu relato. Para o exemplo $1 b$ usou-se o seguinte trecho: 
Exemplo 1b: ((sorri envergonhada e cobre a boca com a mão))

Labov (1972) considera que os elementos avaliados transmitidos pelo narrador nas avaliações encaixadas podem estar presentes não apenas nos trechos que compreendem a Avaliação, mas igualmente em qualquer outro ponto da narrativa.

Uma vez que a Avaliação é caracterizada por uma carga dramática, utilizandose, por exemplo, de recursos prosódicos durante o ato narrado, faz-se necessário uma delimitação do contexto de análise no nível da Unidade Entoacional (EU), pois, segundo Chafe (1990), é a EU que carrega informações quanto às características de organização da fala:

As unidades de entoação representam uma segmentação física do fluxo da fala. Faz sentido pensar em cada um deles como uma verbalização de apenas aquele grupo de informações que está ativo em um determinado momento. Tal cluster pode ser chamado de unidade de ideia. Da evidência de unidades de entoação, a quantidade de informação que pode estar ativa a qualquer momento. (CHAFE, 1990, p. 88).

No ato de narrar, são incorporados pelos narradores às Unidades Entoacionais, aspectos paralinguísticos ou multimodais, tais como gestos, que compõem ou mesmo incorporam aos eventos ou sequência de eventos para enriquecê-lo. Um exemplo do papel importante dos elementos multimodais nas interações verbais é dado por Rilliard e Moraes; Erickson; Shochi (2013), quando afirmaram que as informações faciais funcionam também como um decodificador prosódico das informações no ato de fala.

Neste artigo, selecionou-se para uma análise quali-quantitativa a distribuição dos risos nos eventos avaliativos de 12 narrativas de experiência pessoal que compõem o corpus do presente estudo, cujos procedimentos metodológicos serão descritos em seguida.

\section{Métodos}

Essa seção refere-se à apresentação dos procedimentos metodológicos adotados nesse artigo e demonstra as fases do trabalho, como a caracterização do corpus, a descrição dos participantes, bem como a coleta e a análise dos dados.

\subsection{Análise Quantitativa}

Revista Moara, n. 54, ago-dez 2019 ISSN: 0104-0944 
O material utilizado no presente estudo faz parte de um corpus de narrativas de experiência pessoal (LABOV; WALETZKY, 1967; LABOV, 1972) em que os participantes foram solicitados a narrar sobre algum evento interessante de sua vida. As gravações foram feitas por pesquisadores que tinham um certo grau de intimidade com os participantes, em lugares silenciosos e íntimos do narrador, tais medidas foram tomadas para contribuir consideravelmente para o alto grau de espontaneidade nas gravações.

Os participantes foram recrutados de forma espontânea, a convite dos pesquisadores. Ao todo, participaram 12 narradores, sendo 4 homens e 8 mulheres ${ }^{2}$ residentes no estado do Pará, norte do Brasil. Todos os participantes leram e assinaram um Termo de Consentimento Livre e Esclarecido (TCLE), de acordo com a exigência do Ministério da Saúde e do Comitê de Ética em Pesquisa da Universidade Federal do Pará (UFPA). Após a assinatura do TCLE, eles receberam instruções gerais impressas acerca do experimento.

Cada narrativa foi transcrita nos moldes da Análise da Conversação (MARCUSCHI, 1986) e a transcrição fora necessária para facilitar a análise da sua estrutura formal em consonância com o modelo laboviano (LABOV; WALETZKY, 1967 e LABOV, 1972). Uma vez concluída a análise da estrutura formal das 12 narrativas, procedeu-se ao levantamento dos trechos contendo os eventos avaliativos para a quantificação dos dados.

Para a análise quantitativa, elegeram-se duas variáveis dependentes (do tipo binária). Posteriormente, foram triadas as UEs nas narrativas relativas aos trechos avaliativos. Os resultados da análise quantitativa são apresentados em percentual.

\footnotetext{
${ }^{2}$ As narrativas selecionadas fazem parte de um corpus formado para o trabalho final da disciplina Sociolinguística, do PPGL-UFPA, ofertada no primeiro semestre letivo de 2018, da qual as autoras do presente artigo participaram diretamente como discentes e docente da disciplina. Apesar de ter havido o controle de sexo, escolaridade e localidade de cada narrador gravado, não era objetivo inicial formar uma amostra estratificada com equilíbrio de preenchimento das células sociais. Eis a explicação para o número de narradores do sexo feminino ser superior ao dos narradores do sexo masculino.
}

Revista Moara, n. 54, ago-dez 2019 ISSN: 0104-0944

Recebido em 31/08/2019

Avaliado em 24/11/2019 


\subsection{Análise qualitativa}

Uma vez a análise quantitativa concluída, procedeu-se a uma análise multimodal no software GAT-2. Para esta etapa, de análise qualitativa, foram selecionados trechos avaliativos de quatro narrativas. Selecionamos trechos avaliativos de narrativas compostos por risos e que continham registro em vídeo, para que fosse possível a descrição dos gestos que acompanharam os risos dos trechos avaliativos.

Com base nos critérios adotados, foram selecionados dados de quatro diferentes sujeitos: duas mulheres e dois homens, como descrito no quadro 2.

Quadro 2 - Perfil dos narradores e detalhes sobre as narrativas analisadas

\begin{tabular}{|c|c|c|c|c|c|c|}
\hline $\begin{array}{c}\text { Código } \\
\text { narrador }\end{array}$ & Sexo & Idade & Instrução & Moradia & $\begin{array}{c}\text { Título da } \\
\text { narrativa pessoal }\end{array}$ & $\begin{array}{c}\text { Duração } \\
\text { da } \\
\text { gravação }\end{array}$ \\
\hline RLM1RC01 & Masculino & 18 anos & Ensino superior & Belém (PA) & $\begin{array}{c}\text { O primeiro dia de } \\
\text { aula }\end{array}$ & $1^{\prime} 45^{\prime}$, \\
\hline NSF3NI05 & Feminino & 81 anos & Ensino fundamental & $\begin{array}{c}\text { Santa Bárbara } \\
\text { (PA) }\end{array}$ & $\begin{array}{c}\text { Ser roubada para } \\
\text { casar-se }\end{array}$ & 1 '11', \\
\hline NLM1NI09 & Masculino & 23 anos & $\begin{array}{c}\text { Ensino superior } \\
\text { incompleto }\end{array}$ & $\begin{array}{c}\text { Santa Izabel do } \\
\text { Pará (PA) }\end{array}$ & $\begin{array}{c}\text { Dormindo nos } \\
\text { cultos }\end{array}$ & 1 '58, \\
\hline IPF1NC12 & Feminino & 20 anos & $\begin{array}{c}\text { Ensino superior } \\
\text { incompleto }\end{array}$ & Belém (PA) & $\begin{array}{c}\text { Alagamento na } \\
\text { cidade }\end{array}$ & 2 '53', \\
\hline
\end{tabular}

Elaboração: Das autoras, 2019

Os narradores foram codificados conforme os dados de controle sociolinguístico levados em consideração para as gravações, assim contamos com a composição, primeiramente, das letras iniciais do Nome e Sobrenome dos locutores; seguido do sexo, em que temos: $M$ para masculino e $\mathrm{F}$ para feminino; posteriormente, de faixa etária: número 1 para pessoas até 24 anos, 2 para pessoas de 25 até 60 anos e 3 para pessoas acima de 60 anos.

Levamos em consideração, também, se os participantes possuíam nível superior ou não, recebendo a letra $\mathrm{R}$ os que possuíam e $\mathrm{N}$ os que não possuíam. Do mesmo 
modo, foram codificados conforme o lugar onde moravam (capital ou interior do estado do Pará), codificando I para os moradores do interior e C para os da capital.

Por fim, a sequência no corpus das narrativas que eles ocupavam: RLM1RC01 (RL no primeiro grupo de faixa etária, homem, morador da cidade de Belém, com nível superior completo, sendo o primeiro a ter a narrativa coletada); NSF3NI05 (NS, senhora de mais de 60 anos, moradora de uma cidade no interior do Pará, sem nível superior e a quinta narrativa a ser coletada); NLM1NI09 (NL, homem no primeiro grupo de faixa etária, morador do interior do estado do Pará, sem nível superior e a nona narrativa a ser coletada) e IPF1NC12 (IP: mulher no grupo da primeira faixa etária, não possui nível superior e a décima segunda narrativa a compor o corpus).

Nenhum dos locutores sabia os detalhes do estudo a que se destinavam as gravações.

Para a análise qualitativa dos trechos contendo risos foi utilizado o sistema de transcrição da fala em interação, GAT - Gesprächsanalytisches Transkriptionssystem, sistema de transcrição para análise da conversa (SELTING et al., 2011).

$\mathrm{Na}$ próxima seção, são descritos os resultados das análises quantitativa e qualitativa.

\section{Resultados}

Nesta seção, são apresentados, primeiramente, os resultados da análise quantitativa dos trechos avaliativos contendo risos e, posteriormente, os resultados da análise qualitativa dos dados.

\subsection{Análise quantitativa dos dados}

Ao todo foram identificados 133 trechos avaliativos no corpus inicial das 12 narrativas, dos quais 99 eventos avaliativos do tipo encaixada e 34 do tipo externa, conforme observa-se no gráfico 1, que contém a distribuição dos tipos de avaliação presentes no corpus, com percentual de frequência maior para as avaliações do tipo encaixada. 


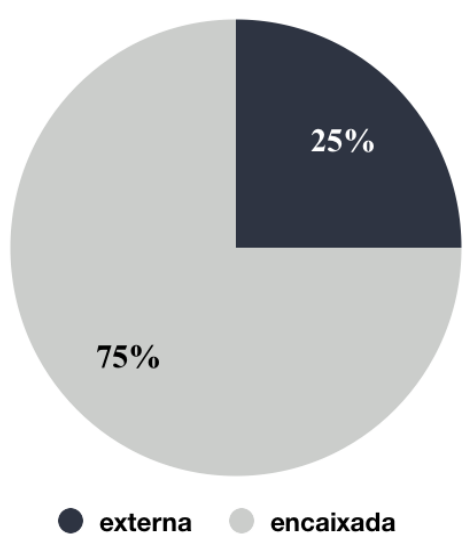

Elaboração: Das autoras, 2019

O gráfico 1 indica claramente uma preferência dos narradores por avaliações do tipo encaixada (75\%) no corpus analisado. Ao procedermos ao levantamento apenas dos trechos avaliativos contendo risos, constatamos que, no corpus em análise, os risos foram identificados categoricamente como avaliações encaixadas.

No exemplo 2 a temos um excerto sobre "o primeiro dia de aula" do informante RLM1RC01 e exemplificamos uma UE contendo risos, segundo a descrição do GAT (SELTING et al., 2011):

Exemplo 2a: "ela só me brigou um pouco e só isso ((risos))"

O quadro 3 contém uma caracterização completa dos eventos avaliativos analisados.

Quadro 3 - Descrição detalhada dos eventos avaliativos contendo risos do corpus

\begin{tabular}{|l|l|l|l|l|l|l|}
\hline \multicolumn{1}{|c|}{ Dados } & Narrativa & \multicolumn{1}{|c|}{$\begin{array}{c}\text { Parte da } \\
\text { narrativa }\end{array}$} & $\begin{array}{c}\text { Sexo do } \\
\text { narrador }\end{array}$ & $\begin{array}{c}\text { Idade do } \\
\text { narrador }\end{array}$ & $\begin{array}{c}\text { Instrução do } \\
\text { narrador }\end{array}$ & $\begin{array}{c}\text { Moradia } \\
\text { do } \\
\text { narrador }\end{array}$ \\
\hline $\begin{array}{l}\text { "Teve uma vez } \\
\text { (risos) (+)que" }\end{array}$ & RLM1RC01 & Orientação & Masculino & 18 anos & Ensino superior & Belém (PA) \\
\hline $\begin{array}{l}\text { "e eu fui na onda } \\
\text { dessa brincadeira } \\
\text { deles fui tacar uma } \\
\text { pedra no meu }\end{array}$ & RLM1RC01 & Complicação & Masculino & 18 anos & Ensino superior & Belém (PA) \\
\hline
\end{tabular}




\begin{tabular}{|c|c|c|c|c|c|c|}
\hline $\begin{array}{l}\text { priMEIro dia de aula } \\
\text { (risos)" }\end{array}$ & & & & & & \\
\hline $\begin{array}{l}\text { "quando a mamãe } \\
\text { foi me buscar na } \\
\text { escola ela me } \\
\text { chamou e eu tava de } \\
\text { costa pra ela me } \\
\text { benzendo todinho } \\
\text { (risos)" }\end{array}$ & RLM1RC01 & Complicação & Masculino & 18 anos & Ensino superior & Belém (PA) \\
\hline $\begin{array}{l}\text { "ela só me brigou } \\
\text { um pouco e só isso } \\
((\text { risos) }) \text { ") }\end{array}$ & RLM1RC01 & Coda & Masculino & 18 anos & Ensino superior & Belém (PA) \\
\hline $\begin{array}{l}\text { "ele gritava banana } \\
\text { ((risos) }) \text { " }\end{array}$ & NSF3NI05 & Complicação & Feminino & 81 anos & $\begin{array}{l}\text { Ensino } \\
\text { fundamental }\end{array}$ & $\begin{array}{l}\text { Santa } \\
\text { Bárbara } \\
\text { (PA) }\end{array}$ \\
\hline $\begin{array}{l}\text { ao final da narrativa, } \\
\text { a narradora sorri. }\end{array}$ & NSF3NI05 & Coda & Feminino & 81 anos & $\begin{array}{l}\text { Ensino } \\
\text { fundamental }\end{array}$ & $\begin{array}{l}\text { Santa } \\
\text { Bárbara } \\
\text { (PA) }\end{array}$ \\
\hline $\begin{array}{l}\text { e::... }((\text { risos })) \ldots \text { eu } \\
\text { dormi no culto } \\
\text { também... }\end{array}$ & NLM1NI09 & Orientação & Masculino & 23 anos & $\begin{array}{l}\text { Ensino superior } \\
\text { incompleto }\end{array}$ & \begin{tabular}{|l} 
Santa \\
Izabel do \\
Pará (PA)
\end{tabular} \\
\hline $\begin{array}{l}\text { "nesse dia foi foi } \\
\text { engraçado, ((sorrir)) } \\
\text { tudo por causa disso } \\
\text { que (+) eu acordei } \\
\text { cedo (+) aí enfrentei } \\
\text { o engarrafamento, } \\
\text { caiu um:: dilúvio em } \\
\text { Belém (+) aí não } \\
\text { teve aula pra } \\
\text { gente::" }\end{array}$ & IPF1NC12 & Resumo & Feminino & 20 anos & $\begin{array}{l}\text { Ensino superior } \\
\text { incompleto }\end{array}$ & Belém (PA) \\
\hline
\end{tabular}

Elaboração: Das autoras, 2019

De acordo com o quadro 3, todos os oito registros de avaliações com 'risos' encontrados foram do tipo Encaixada, categoricamente. Ao verificarmos a localização desses eventos avaliativos, considerando a seção da narrativa de experiência pessoal, constatamos que três eventos avaliativos estavam em posição de Complicação das narrativas; dois em posição de Orientação e dois em posição de Coda, e um registro na posição Resumo, conforme o gráfico 2. 


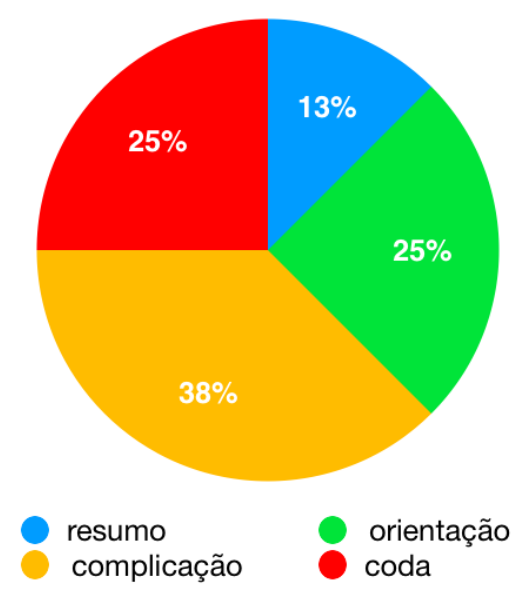

Elaboração: Das autoras, 2019

Um último levantamento realizado na análise quantitativa diz respeito à ocorrência de risos nos trechos avaliativos associados a outro tipo de gesto corporal. Houve uma predominância de produção de risos na composição de trechos avaliativos do tipo Encaixada acompanhados de algum gesto corporal. Apenas uma ocorrência de trecho avaliativo com risos, identificada na Orientação, e que foi produzida sem acompanhamento de outro gesto corporal. É justamente o refinamento dessas análises é que será apresentado na seção seguinte.

\subsection{Análise qualitativa dos dados}

$\mathrm{Na}$ análise qualitativa dos dados, optamos por apresentar individualmente cada evento avaliativo por narrativa de experiência pessoal. Para melhor entendimento do papel associado ao riso na composição dos trechos avaliativos do tipo encaixada, há necessidade de contextualizar sua ocorrência, considerando o tema de cada narrativa e uma síntese do evento narrativo em si. 


\subsubsection{O primeiro dia de aula (RLM1CO1)}

A narrativa era sobre a transferência do narrador de um colégio de Belém, Pará, para outro em Tucuruí, Pará, no meio do semestre escolar, mas, logo no primeiro dia de aula na nova escola, o narrador envolveu-se em uma confusão. O sujeito narra que, ao chegar ao colégio, identificou que os colegas de turma costumavam brincar de lançar pedras de um barranco nos arredores da instituição e decidiu entrar na brincadeira. No entanto, ele acidentalmente atirou uma pedra em um colega de classe, Lohan, que o denunciou para a direção. Em virtude dessa situação, o narrador foi chamado pela direção da escola em seu primeiro dia de aula, o que gerou, nele próprio um sentimento de medo. A mãe do narrador, ao chegar na escola, o viu se benzendo e questionou o que havia acontecido, então ele explicou a situação. A genitora do narrador, contudo, chamou sua atenção brevemente e o ocorrido não gerou problemas maiores.

Eis como ocorreram os eventos avaliativos do tipo encaixado nesta narrativa.

a) Avaliação Encaixada na Orientação

Ao iniciar o relato com as informações sobre a localização temporal, o narrador realiza um avaliação indireta do fato de ter jogado uma pedra em um colega na escola em seu primeiro dia de aula, caracterizado pelo riso.

\section{Imagem 1 - Janela do GAT na descrição dos gestos de RLM1C01}

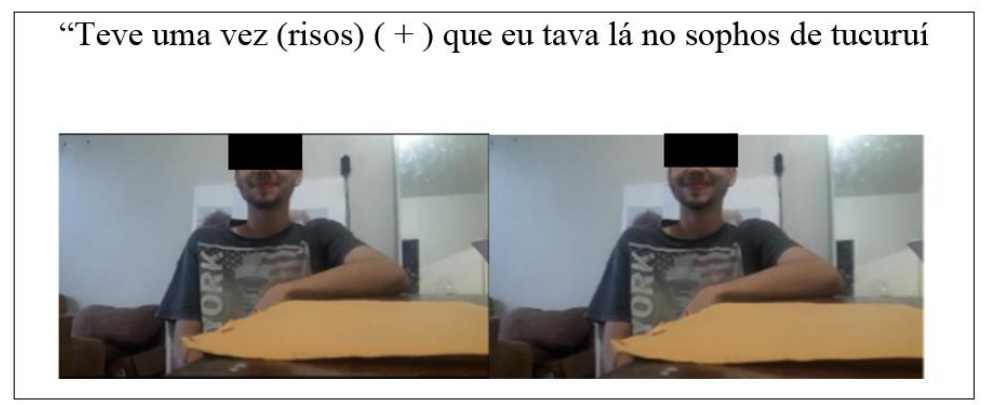

Foto: Das autoras, 2018

b) Avaliação Encaixada na Complicação

Nesta narrativa houve avaliações encaixadas nas duas situações de Complicação. A primeira ocorre quando o narrador relata ter jogado uma pedra em um colega na Revista Moara, n. 54, ago-dez 2019 ISSN: 0104-0944 
escola em seu primeiro dia de aula, caracterizada pela composição de gestos: risos e o movimento com uma das mãos.

Imagem 2 - Janela do GAT na descrição dos gestos de RLM1C01

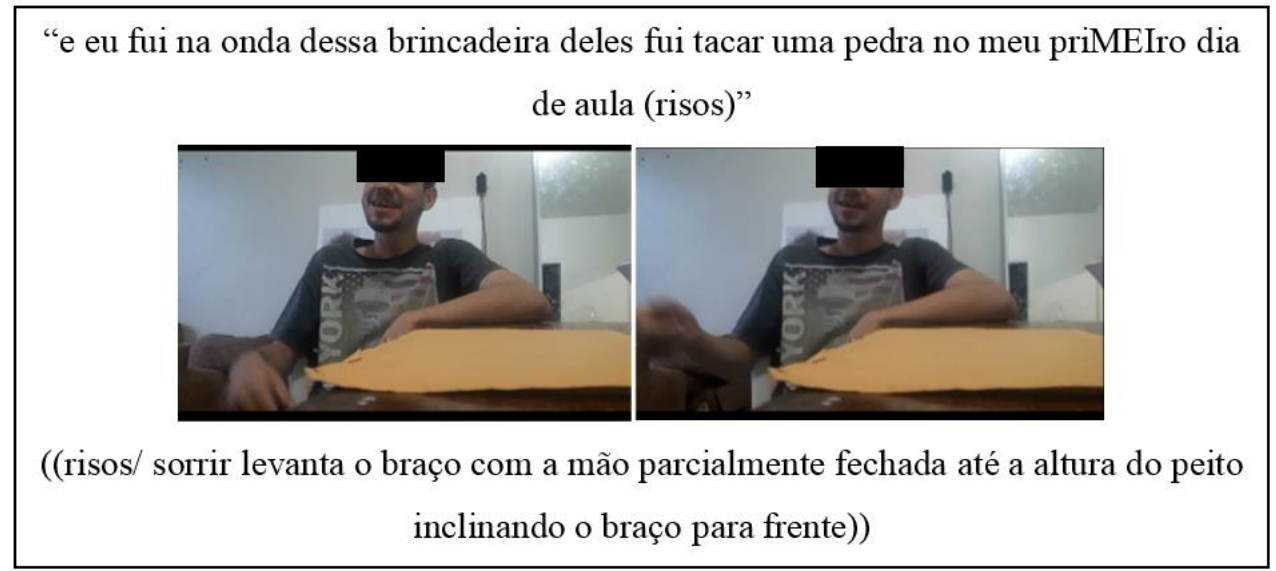

Foto: Das autoras, 2018

c) Avaliação Encaixada na Complicação

Na sequência dos eventos, a segunda ocorrência de Avaliação Encaixada aparece no relato do narrador quando sua mãe está na escola para buscá-lo e fica sabendo do ocorrido, e ele, com medo de sua reação, diz ter se benzido, ato caracterizado pela composição de gestos: risos e o movimento de cruz com a mão.

Imagem 3 - Janela do GAT na descrição dos gestos de RLM1C01

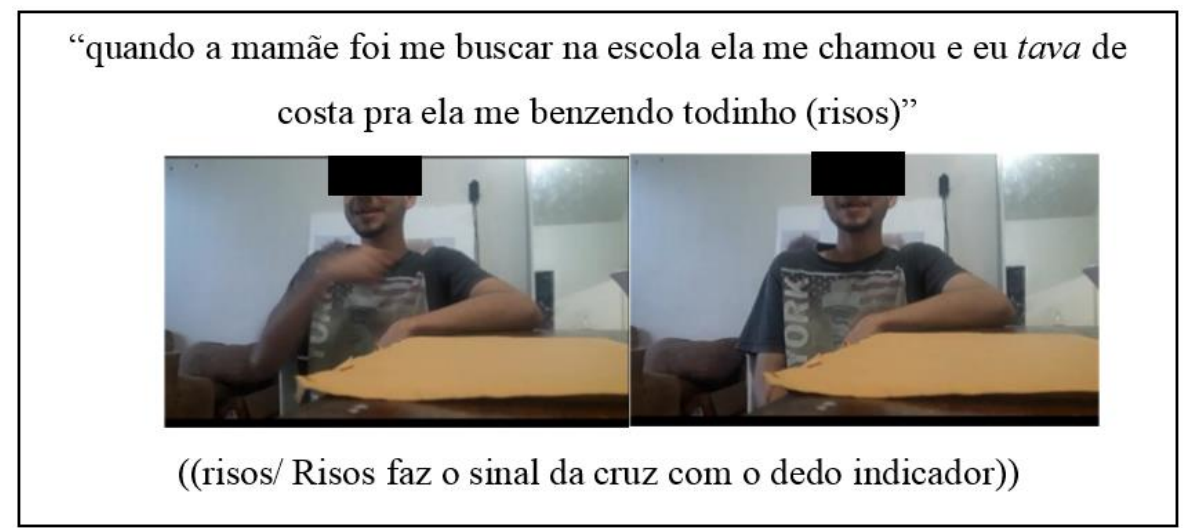

Foto: Das autoras, 2018

Revista Moara, n. 54, ago-dez 2019 ISSN: 0104-0944 
d) Avaliação Encaixada na Coda

No relato em que o narrador apresenta informações sobre como a mãe reagiu ao mau comportamento dele na escola, aparece uma Avaliação Encaixada caracterizada pelo riso.

Imagem 4 - Janela do GAT na descrição dos gestos de RLM1C01

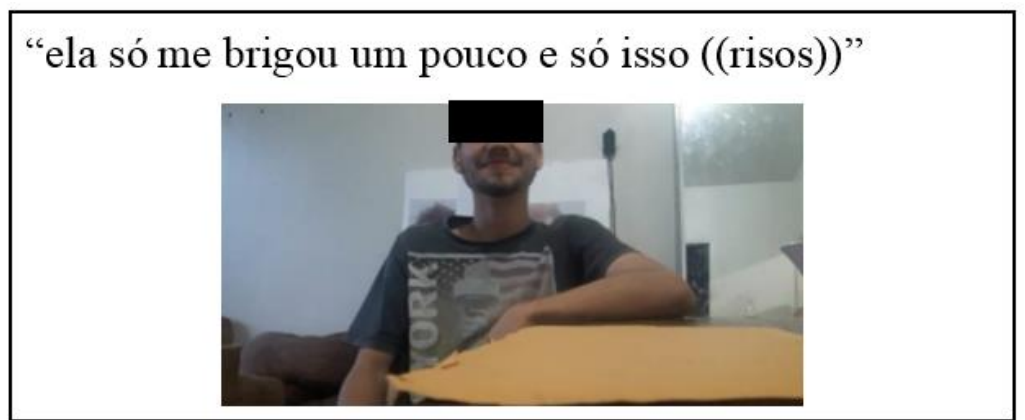

Foto: Das autoras, 2018

Observamos nessa narrativa o evento do riso duas vezes em posição de Complicação. O primeiro logo no início do ato narrativo, ou seja, na Orientação, e o segundo na Coda. O narrador já inicia sua narrativa com um sorriso, como em um ato de deixar o rosto risível, o que pode ser caracterizado pelas primeiras palavras: "teve uma vez" acompanhadas por um riso ao final do enunciado, além de sorrir emitindo som e inclinando a cabeça para a frente.

\subsubsection{Ser roubada para casar-se (NSF3NI05)}

A narrativa trata de um casamento à moda do início do século $\mathrm{XX}$ em cidades interioranas na região Norte e Nordeste do Brasil. Uma senhora interiorana do Maranhão conta como foi roubada por seu namorado aos 13 anos de idade para se casarem. Dando conta de seu sumiço, o pai entra em desespero e grita por ela, a mãe preocupada com o que os vizinhos pensariam pede para que ele não grite, e ele, em resposta, manda um gesto de banana com os braços para vizinhança. Dias depois, o casamento acontece em uma igreja central da cidade.

Eis como ocorreram os eventos avaliativos do tipo encaixado nesta narrativa. 
a) Avaliação Encaixada na Complicação

Na Complicação, que dá sequência dos eventos da narradora, ela relata a reação do pai ao ser repreendido por estar gritando o seu nome pela vizinhança ao se dar conta de que a narradora havia fugido de casa, aparece uma avaliação indireta caracterizada pela composição de gestos: risos e o movimento com a mão na saia.

Imagem 5 - Janela do GAT na descrição dos gestos de NSF3NI05

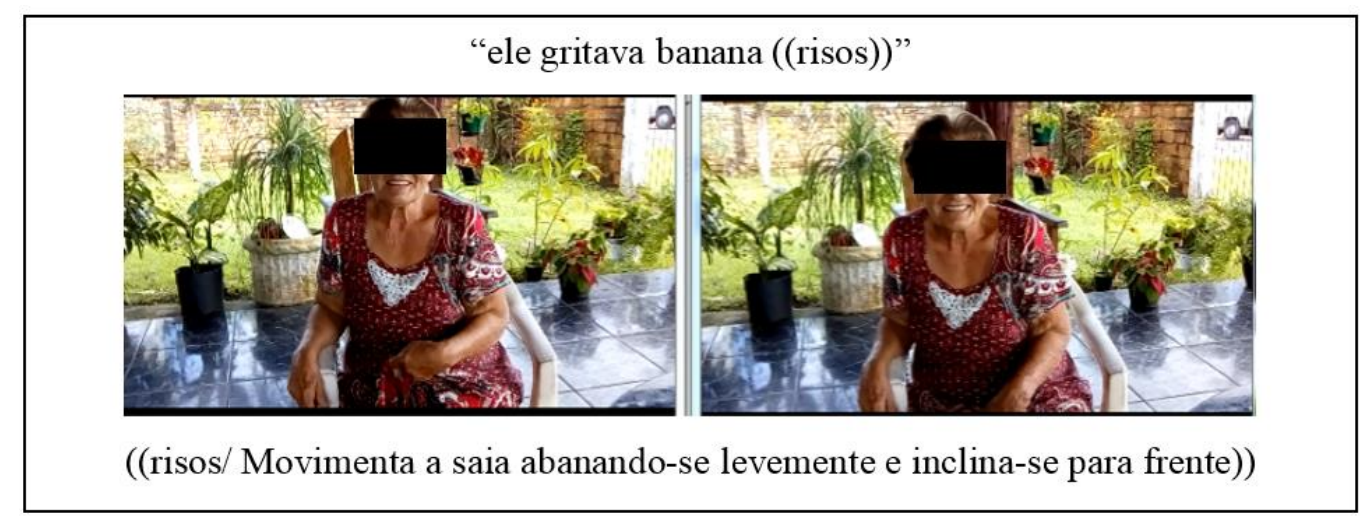

Foto: Das autoras, 2018

b) Avaliação Encaixada na Coda

Ao finalizar a avaliação descrita no subitem a, a narradora, em um encadeamento fora dos eventos, sorri envergonhada compondo gestualmente o fato, caracterizado pela composição de gestos: riso, movimento com a mão até a boca e inclinando a cabeça para o lado. A narradora não emite declaração com palavras.

Imagem 6 - Janela do GAT na descrição dos gestos de NSF3NI05

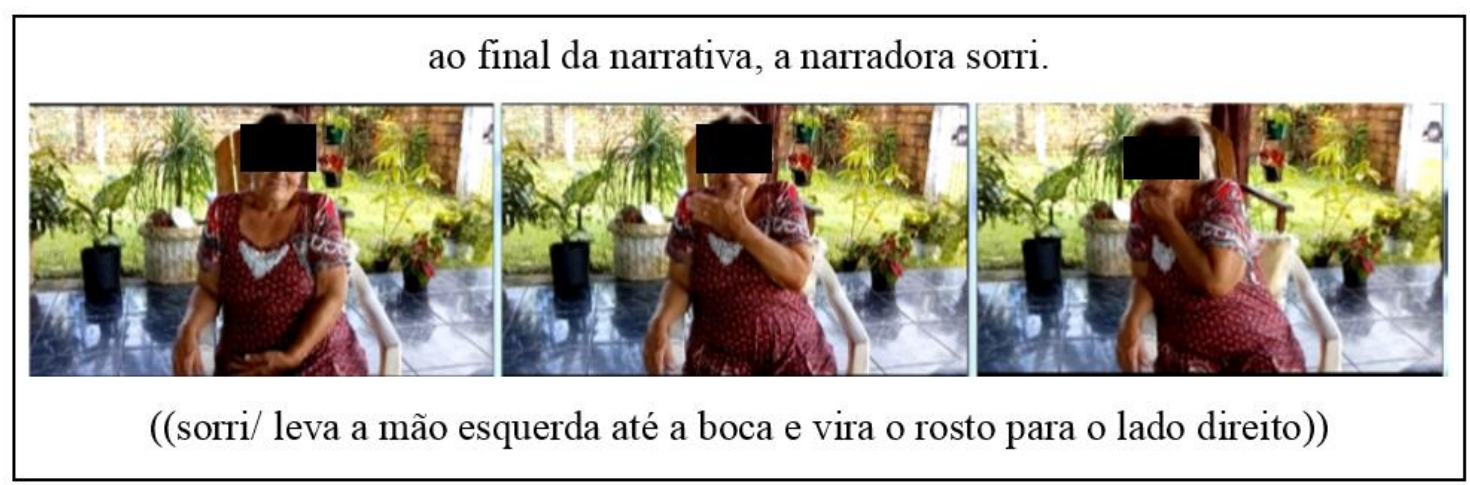

Foto: Das autoras, 2018

Revista Moara, n. 54, ago-dez 2019 ISSN: 0104-0944

Recebido em 31/08/2019

Avaliado em 24/11/2019 


\subsubsection{Dormindo nos cultos (NLM1NIO9)}

O narrador iniciou sua carreira musical na igreja ainda na infância e teve algumas experiências engraçadas que até hoje marcam sua vida e o tornam conhecido entre as pessoas, por exemplo, o ato de dormir nos cultos. Ele destacou três histórias que marcaram sua vida. A primeira aconteceu por volta dos seis ou sete anos. Nesse período, ele tocava bateria e, em um dia de culto, acabou dormindo. Como o chão da igreja era de barro, o formato do rosto do narrador ficou marcado no chão e ele sempre é motivo de risada pela situação ocorrida. A segunda aconteceu por volta dos oito anos e o narrador ainda tocava bateria. Durante um culto, ele acabou dormindo novamente e relatou que estava em cima de uma caixa de som e no momento em que caiu, bateu a orelha no canto da caixa e quase a perdeu. A terceira foi por volta dos onze anos no estado do Piauí e o narrador estava tocando contrabaixo. Na hora da pregação (sermão bíblico), o narrador dormiu e o instrumento, que estava ao lado, caiu no chão. Toda igreja ficou espantada com o barulho e o instrumento ficou todo quebrado causando o maior prejuízo.

\section{a) Avaliação Encaixada na Orientação}

Nesta narrativa, houve apenas um caso de evento avaliativo do tipo encaixado, identificado na Orientação da narrativa. Ao informar o local do relato, o narrador realiza um avaliação indireta do fato de ter dormido, caracterizado pela composição de gestos: risos e o movimento da cabeça de forma acertiva.

\section{Imagem 7 - Janela do GAT na descrição dos gestos de NLM1NI09}

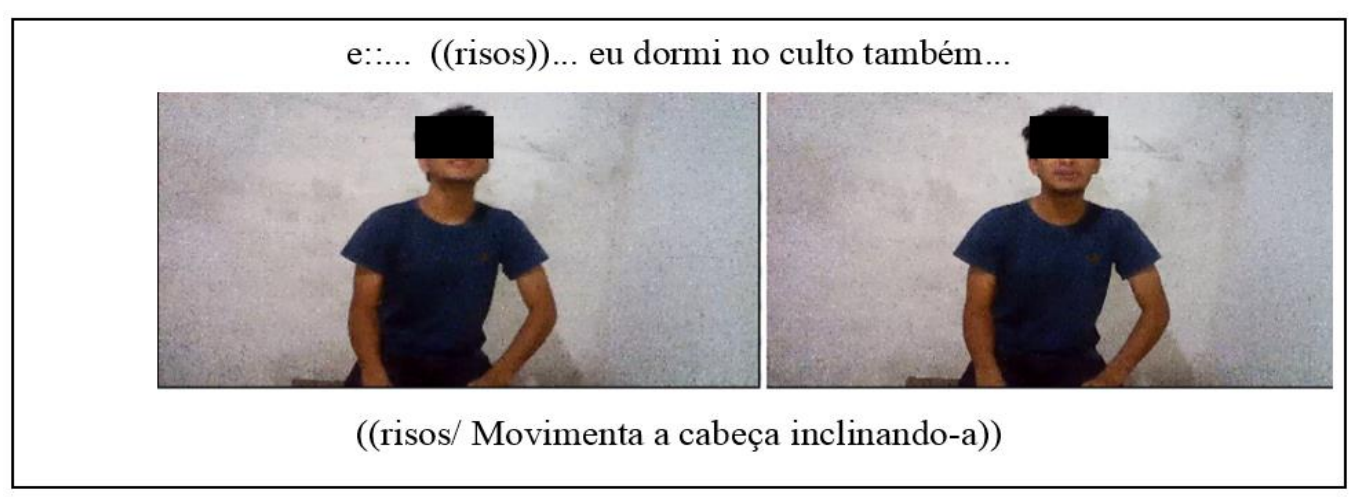

Foto: Das autoras, 2018

Revista Moara, n. 54, ago-dez 2019 ISSN: 0104-0944 
Quanto ao riso nessa narrativa, o que chama atenção é que o narrador, durante toda narração de sua experiência, o faz sorrindo, como se antecipasse para o público que a sequência dos eventos a serem contados são realmente engraçados. Mas este riso, que está descrito como avaliação, é o que a compõe, junto ao gesto de afirmar com a cabeça, que se destaca, pois, além de acompanhar a fala: "eu dormi no culto também" tem uma parada antes da própria fala. Como se constatasse que o fato é realmente irônico.

\subsubsection{Alagamento na cidade (IPF1NC12)}

A narradora descreve a dificuldade que ela e seus amigos passaram em um dia de muita chuva na cidade, e que, por ter faltado alguns dias às aulas da faculdade, com medo de ser reprovada por falta, acordou nesse dia bastante cedo, mas apesar desse esforço, não conseguiu chegar no horário, e mesmo que tivesse conseguido, não teria aula, pois devido ao volume de chuva naquele dia, as atividades na faculdade em que a narradora estudava foram suspensas.

\section{a) Avaliação Encaixada no Resumo}

Nesta narrativa, houve apenas um caso de evento avaliativo do tipo encaixado, identificado no Resumo da narrativa. Ao sintetizar o relato, a narradora realiza uma avaliação indireta do ocorrido com o uso de uma composição de gestos: o sorriso, juntamente com o ato de fechar os olhos e levar a mão a cabeça.

\section{Imagem 8 - Janela do GAT na descrição dos gestos de IPF1NC12}

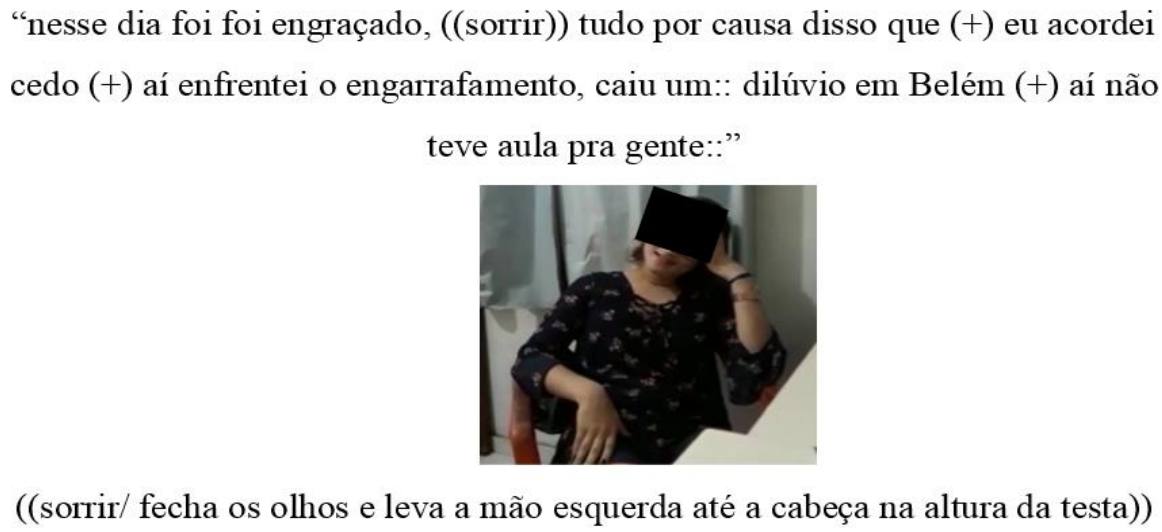

((sorrir/ fecha os olhos e leva a mão esquerda até a cabeça na altura da testa))

Foto: Das autoras, 2018

Revista Moara, n. 54, ago-dez 2019 ISSN: 0104-0944 
A narradora apresenta uma composição de gestos ao iniciar o resumo de sua experiência, junto ao sorriso, ela fecha os olhos e leva a mão esquerda até a cabeça na altura da testa, e então mantém esta posição e o riso até o final da declaração.

A análise quantitativa aqui realizada subsidiaram informações para a composição das descrições na avaliação qualitativa de gestos associados ao riso nas Avaliações Encaixadas.

Os resultados apresentados acima demonstram que os gestos constituem uma linguagem corporal que se unem às UEs para demonstrar uma unidade de ideia. Segundo Chafe (1990), o que dá evidência de Unidades de Entoação é a quantidade de informação que pode estar ativa a qualquer momento, ou seja, o quanto está contida em uma unidade de ideia, mas os resultados das análises dos dados multimodais aqui apresentados nos levam a concluir que os gestos fazem parte dessa UE por comporem partes fundamentais nas narrativas.

Apesar de não ter sido objeto de investigação do presente artigo, em alguns momentos, é possível perceber a associação direta da velocidade da fala com os gestos; no caso do narrador NLM1NI09, há uma pausa e um riso no discurso antes de constatar que dormiu mais uma vez, diminuindo, assim, a velocidade da fala para dar ênfase na informação seguinte. No caso da narradora IPF1NC12 há prolongamento de vogais finais por duas vezes na oração em que ela constata que, devido ao temporal, ela não teve aula, apesar de ter acordado cedo, junto ao gesto de levar a mão a cabeça e rir, portanto, o prolongamento das vogais dá ênfase em duas informações importantes: “(...) um: dilúvio (...)” e “(...) gente: (...)”, a primeira informação sobre a quantidade de chuva e a segunda sobre não ter tido aula para a turma da informante.

Esses trechos avaliativos se constituem de situações que, à primeira vista, demonstram constrangimento, porém na avaliação que os narradores imprimem no ato de recontar suas experiências, expressam um ato risível perante o que naquele momento lhes fora constrangedor.

Por essas descrições e pelo forte apelo semântico carreado pelos elementos não verbais, em especial, os risos, aqui neste artigo, inferimos que a Avaliação Encaixada nessas situações é enriquecida ou acrescida dos recursos linguísticos paralinguísticos e gestuais.

Revista Moara, n. 54, ago-dez 2019 ISSN: 0104-0944 


\section{Conclusões}

O presente estudo teve por objetivo avaliar em que medida as avaliações encaixadas nas narrativas de experiência oral são enriquecidas com recursos paralinguísticos e gestuais. Além disso, procuramos investigar qual o peso que o riso tem nesse processo de subsidiar as Avaliações Encaixadas. Para isso, um protocolo experimental , o GAT (SELTING et al., 2011), foi utilizado para descrever gestualmente narrativas de experiência pessoal (LABOV; WALETZKY, 1967; LABOV, 1972), precedida de uma análise quantitativa elementar.

Os resultados aqui apresentados corroboram o que a literatura especializada já havia observado quanto à tradição oral e sua carga dramática, tal como para Menezes de Souza (2001), ao afirmar que uma narrativa é um ato social altamente dinâmico, muito diferente do ato solitário de escrever e ler um texto escrito, trazendo consigo uma carga dramática enriquecida, muitas vezes, pelos gestos.

O fato de os risos presentes nesse corpus estarem, com exceção de apenas um dos registros, acompanhados por um conjunto de gestos e de terem ocorrido preferencialmente nas avaliações do tipo Encaixadas no corpus, demonstram que, como já apontado por Britton e Kerbrat-Orecchioni (1996), os aspectos paraverbais ou não verbais desempenham um papel importante nas interações verbais.

\section{REFERÊNCIAS}

CHAFE, W. Some things that narratives tell us about the mind. In: PELLEGRINI, A.; BRITTON, B. (Org.). Narrative thought and narrative language. Hillsdale: Lawrence Erlbaum, 1990. p. 79-98.

BRITTON, A.; KERBRAT-ORECCHIONI, C. La conversation. Paris: Éditions du Seuil, 1996.

LABOV, W; WALETZKY, J. Narrative Analusis: oral versions of personal experience. In: Helm, J. (Org). Essays on the verbal and visual arts. Washington: University of Washington Press, 1967.

LABOV, William. Padrões sociolinguísticos. São Paulo: Parábola, [1972] 2008.

Revista Moara, n. 54, ago-dez 2019 ISSN: 0104-0944 
MACHADO, Rosa Helena Blanco. Algumas questões sobre a narrativa: elementos essenciais e elementos não essenciais da narrativa. Dissertação (Mestrado em Linguística) - Instituto de Estudos da Linguagem, Universidade Estadual de Campinas, Campinas, São Paulo, 1980.

MARCUSCHI, L. A. Análise da Conversação. São Paulo: Ática; 1986.

MENEZES DE SOUZA, Lynn Mario T. De estória à história: a escrita indígena no Brasil. Revista da Biblioteca Mário de Andrade (Literatura e diversidade cultural), v. 59, p. 69-72, 2001.

OLIVEIRA JR., M. Prosodic features in spontaneous narratives. Tese (Doutorado em Liguística) - Simon Fraser University, Vancouver, 2000.

RILLIARD, A.; MORAES, J. A.; ERICKSON, D.; SHOCHI, T. Social affect production and perception across languages and cultures - the role of prosody. Leitura Maceió, v.52, p. 15-41, jul./dez. 2013.

SELTING, M. et al. Um sistema para transcrever a fala-em-interação: GAT 2 (Tradução de Ulrike Schröder et al.). Veredas Atemáticas, 2/2016. 